Literature Reviews

\title{
About Bell Helicopter FCX-001 Concept Aircraft-A Short Review
}

\author{
${ }^{1}$ Relly Victoria Petrescu, ${ }^{2}$ Raffaella Aversa, \\ ${ }^{3}$ Bilal Akash, ${ }^{4}$ Juan Corchado, \\ ${ }^{2}$ Antonio Apicella and ${ }^{1}$ Florian Ion Tiberiu Petrescu \\ ${ }^{1}$ ARoTMM-IFToMM, Bucharest Polytechnic University, Bucharest, (CE), Romania \\ ${ }^{2}$ Advanced Material Lab, Department of Architecture and Industrial Design, \\ Second University of Naples, 81031 Aversa (CE), Italy \\ ${ }^{3}$ Dean of School of Graduate Studies and Research, American University of Ras Al Khaimah, UAE \\ ${ }^{4}$ University of Salamanca, Spain
}

Article history

Received: 16-06-2017

Revised: 23-06-2017

Accepted: 29-06-2017

Corresponding Author: Florian Ion Tiberiu Petrescu ARoTMM-IFToMM,

Bucharest Polytechnic

University, Bucharest, (CE), Romania

E-mail: scipub02@gmail.com
Abstract: Bell Helicopter is always preparing beautiful surprises for us, so this year has not been outdone and has revealed its vision of its future aircraft model FCX-001, a true vertical elevator, ment to can climb to high altitudes in a record time, with an enviable dynamics and maneuverability. The first appearance of the new model FCX-001 took place at Heli Expo 2017 in Dallas, Texas, where the new concept of the aircraft was presented in this highly stylized form. The aircraft appeared in the Bell stand, both in the form of a large-scale layout and in the virtual reality by using immersive helmets, the two-engine ship incorporating some of the new technologies currently under development at Bell and it is very likely to mature in the near future. At first glance, you are astonished at a cockpit that is totally devoid of physical controls, as if the ship were to run alone, fully automated. Notable elements in the design of the FCX-001 include a fan-driven anti-torque system, hybrid propulsion system, main rotor blade tips, extensive use of fuselage glass, winged doors and the use of augmented reality in the cockpit to control the aircraft. On the very roomy cabin ceiling of the aircraft, configured for only eight passengers in the Heli-Expo model, but able to adapt up to 12 passengers, Bell introduced a "drop-down" control module to allow personalization maximum and increased passenger comfort. The concept is provided with various modules that provide passengers with the ability to adjust their own things, such as cabin light intensity, interior temperature, or infotainment system. When looking closely at the new FCX-001 concept, starting with the back of the aircraft, it does not have a tail rotor (which is essential and notable for Bell's new model). In order to achieve the anti-torque instead, a new multi-rotor system is needed in the hood. It gives the aircraft the ability to push in both directions and also has vector control of the traction, also allowing it to give up a horizontal stabilizer. The antitorque system is acted by an electric motor as part of a hybridized propulsion system. At the top of the aircraft, the main rotor blades (morphing) have an attractive design. At the same time, technology aims to allow the tip of each blade to move between the different flight regimes, just like a "swing wing" on an airplane to maximize efficiency and performance and reduce noise. The actual airframe of the aircraft is also very different from what Bell used in the past. In terms of ladder, the FCX-001 is slightly larger than a Bell 412 both in terms of its length and width, its new lines and its use of massive glass exhisbiting some production challenges that rely on the new composite structures, today so widely used in the aviation and aerospace industries.

Keywords: Bell Helicopter, New Aircraft Concept, Vertical Elevator, High Altitudes, Modern Ship, Dynamics, Heli Expo, Dallas Texas

(C) 2017 Relly Victoria Petrescu, Raffaella Aversa, Bilal Akash, Juan Corchado, Antonio Apicella and Florian Ion Tiberiu Petrescu. This open access article is distributed under a Creative Commons Attribution (CC-BY) 3.0 


\section{Introduction}

Founded in 1935 under the name of Bell Aircraft Corporation, today Bell Helicopter is an important aerospace company that continues to set the pace for industry and expands the scope of the vertical elevator. Being an industry leader with unparalleled global recognition, the name Bell Helicopter was the first to obtain commercial helicopter certification. Throughout its existence (over 80 years), Bell Helicopter has delivered over 35,000 aircraft to customers around the world (Petrescu and Petrescu, 2011; 2012; 2013a; 2013b; 2013c).

With always thinking ahead in advanced concepts, Bell Helicopter has managed to invent and design jet planes. These unique aircraft stand up like a helicopter, then fly like a plane at a double speed, three times the payload and five times the traditional helicopter. The big concern Bell worked for both the aerospace and the aerospace industries, the differences between them being significant.

Headquartered in Fort Worth, Texas, Bell Helicopter has additional plants in Amarillo, Texas and Mirabel, Canada and major supply and logistics centers in Amsterdam, Prague, Canada and Singapore as well as in the United States. As the world's leading provider of vertical lift aircraft, Bell Helicopter continues to provide superior service to all its customers.

\section{Materials and Methods}

Bell Helicopter is always preparing beautiful surprises for us, so this year has not been outdone and has revealed its vision of its future aircraft model FCX001, a true vertical elevator, ment to can climb to high altitudes in a record time, with an enviable dynamics and maneuverability (Johnson, 2017).

The first appearance of the new model FCX-001 took place at Heli Expo 2017 in Dallas, Texas, where the new concept of the aircraft was presented in this highly stylized form.

The aircraft appeared in the Bell stand, both in the form of a large-scale layout and in the virtual reality by using immersive helmets, the two-engine ship incorporating some of the new technologies currently under development at Bell and it is very likely to mature in the near future.

At first glance, you are astonished at a cockpit that is totally devoid of physical controls, as if the ship were to run alone, fully automated. Notable elements in the design of the FCX-001 include a fan-driven anti-torque system, hybrid propulsion system, main rotor blade tips, extensive use of fuselage glass, winged doors and the use of augmented reality in the cockpit to control the aircraft (Johnson, 2017).

On the very roomy cabin ceiling of the aircraft, configured for only eight passengers in the Heli-Expo model, but able to adapt up to 12 passengers, Bell introduced a "drop-down" control module to allow personalization maximum and increased passenger comfort. The concept is provided with various modules that provide passengers with the ability to adjust their own things, such as cabin light intensity, interior temperature, or infotainment system (broadcast material that is intended both to entertain and to inform; information and documentation, in the hand of corporate interests in TV-land, have become practices of the past, easily replaced by infotainment and broadcast excuses for advertising spots).

During a revelation of the concept to the industry, Bell CEO Mitch Snyder said the FCX-001 was inspired by the automotive concept of car makers for major car series (Johnson, 2017).

"We said: Let's get the same thing at HAI [HeliExpo] this year. Come with our concept of aircraft, take the technologies that we have worked-not all but some of them-and apply them to an aircraft concept and let people see what we do and the ideas that we have them."

"This is a different Bell, this is a different place we go and this gives you a glimpse of what we work without showing you everything. So some of these technologies are there and some of them are not yet, but some will mature faster than others, but the main thing is that you see different lines, a different look and a different sense of what Bell Helicopter can be (Johnson, 2017).

When looking closely at the new FCX-001 concept, starting with the back of the aircraft, it does not have a tail rotor (which is essential and notable for Bell's new model). In order to achieve the anti-torque instead, a new multi-rotor system is needed in the hood. It gives the aircraft the ability to push in both directions and also has vector control of the traction, also allowing it to give up a horizontal stabilizer. The anti-torque system is acted by an electric motor as part of a hybridized propulsion system (Johnson, 2017).

"We can talk about a propulsion system that is removed from the main propulsion unit and moved down with the gearbox (a gearbox of 45 degrees), that is, the propulsion system has been changed as a position from its usual site just in the location of the mechanical transmission, thus obtaining a compact, efficient, modern, new, inspired model. We can talk about a total system change, total, on the FCX-001 aircraft. Electricity is the method of distribution of the aircraft, fact using cables and a generator near the thermal engine up, the system culminating with electric motors (Fig. 1). 

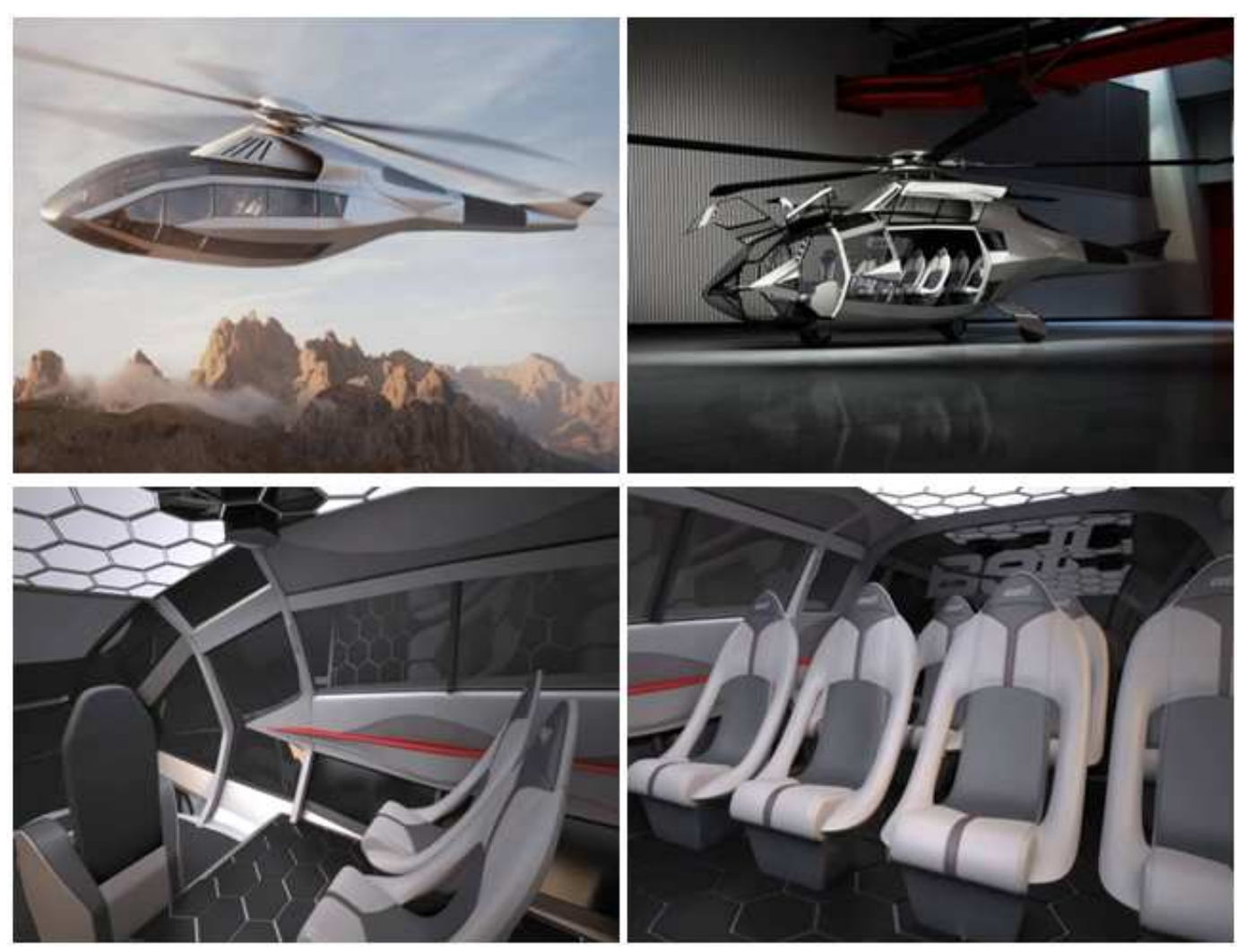

Fig. 1 Bell helicopter FCX-001 concept aircraft. Source: Johnson (2017)

\section{Results}

At the top of the aircraft, the main rotor blades (morphing) have an attractive design. At the same time, technology aims to allow the tip of each blade to move between the different flight regimes, just like a "swing wing" on an airplane to maximize efficiency and performance and reduce noise.

The actual airframe of the aircraft is also very different from what Bell used in the past. In terms of ladder, the FCX-001 is slightly larger than a Bell 412 both in terms of its length and width, its new lines and its use of massive glass exhibiting some production challenges that rely on the new composite structures, today so widely used in the aviation and aerospace industries (Aversa et al., 2016a; 2016b; 2016c; 2016d; 2016e; 2016f; Mirsayar et al., 2017).

Inside, the FCX-001 has only one pilot seat designed for the aircraft to support only one pilot, generally running on the automatic pilot or even in automated modes like unmanned aircraft.

First of all, removing all extra buttons with important or less important roles, which in the course of time deteriorates, gets dirty and which in most cases is useless and even tangles not just the cabin but distracts the pilot from the main objectives and the essential controls. All button functions are replaced by computer assistance and artificial intelligence, allowing the pilot to relax and focus only when special situations arise.

The pilot no longer has to keep track of a set of parameters of the aircraft in flight on various monitors, all parameters being automatically controlled by the software. The pilot now only performs mission control and only takes on important flight safety functions.

In front of the pilot's seat is a clear field of view, without obstacles created by any display or controls. They will be delivered in the form of an augmented reality through a headset that can create their own workspace.

The idea is that the headset will recognize the hands of the pilot in space, allowing them to create and transfer different screens around the cockpit and even anchor them at certain points in space as in advanced software so they do not move when the pilot moved his head, remaining in his field of view.

"It's a futuristic, exciting concept that lets you customize the flight package for any pilot and it can extract the commands it really needs when it really needs it." Automatic directives can be set and only feedback can be obtained Instead of always touching the screen, Bilbrey said: "Microsoft HoloLens is a good example that exists today, but obviously from a conceptual point of view, we hope technology advances and can work with our flight systems." 
In the near term, Drennan said: That "Bell is already running a test bench for anti-torque fan technology and at the same time setting up a hybrid system" (Johnson, 2017).

\section{Discussion}

The new model FCX-001 presented by Bell looks superb and incorporates many new modern features that can be envied by other helicopter manufacturers.

The new concept is stylish, futuristic, stylized, interesting, simplified apparently from a constructive point of view, but in fact much more complex with powerful software that can emulate all the controls and pilot panels.

Some readers of the original article, after which this review was taken (Johnson, 2017), imply the existence of a similar project at Kudos Company, claiming that the ones there tested much better: vibratory and shear loads in the glass, unloading the air wings, modeling the button NOTAR AND VR windows, removing adjacent trees (Johnson, 2017). The authors of this review are convinced that Bell has tested all these features, even though they have not been shown in the short presentation made at Heli-Expo 2017 in Dallas, Texas.

David commented on March 8, 2017 at 1:53 am: Where is the protection against bird blows, protection against dust, snow or intake? Wire protection? Elegant and fanciful yes, but where are the ultra-aerial antennas? I'm an ex-BHT test pilot for over 20 years. Beyond the imagination of the new generation of helicopters, the rotors will soon be obsolete (Johnson, 2017).

It is supposed that all of these issues have already been tested or will be in the future after the first presentation.

Some pilots are afraid of this type of concept without buttons, handles, devices, (not physically built), replaced (emulated) by software.

The new concept of driving with the software inspires the admiration and the fear of the pilot that he could be overcome and at a time of disruption of the software there could be a catastrophe in the absence of a classic, manual, mechanical, physical command. Pilot Bryan $\mathrm{W}$ goes so far as to say that the fear of driving this is so great that experienced pilots will not accept to become soft-assisted robots and to do so unless they will need a lot of money (Johnson, 2017). This is what we believe is the essence. After airplanes without pilots, pilots are now fully coordinated by a central, universal system through satellites, computers, electronics, robotics and soft. The pilot no longer depends only on his reaction capabilities, but to the greatest extent he is permanently coordinated by software. Somehow the pilot becomes a robot and in some extreme situations he can't have the possibility of his will.

\section{The Basic Problem of the Concept}

If the software interrupts even for a second, if it catches a virus, all the emulged commands in the software disappear (even the pilot's lever hand), the pilot becomes powerless, he can only then say his last prayer.

Such a concept contravenes the aviator's ethics and does not even respect the basic rules of flight safety from the start.

\section{Conclusion}

Bell Helicopter is always preparing beautiful surprises for us, so this year has not been outdone and has revealed its vision of its future aircraft model FCX001, a true vertical elevator, ment to can climb to high altitudes in a record time, with an enviable dynamics and maneuverability. The first appearance of the new model FCX-001 took place at Heli Expo 2017 in Dallas, Texas, where the new concept of the aircraft was presented in this highly stylized form. The aircraft appeared in the Bell stand, both in the form of a large-scale layout and in the virtual reality by using immersive helmets, the twoengine ship incorporating some of the new technologies currently under development at Bell and it is very likely to mature in the near future. At first glance, you are astonished at a cockpit that is totally devoid of physical controls, as if the ship were to run alone, fully automated. Notable elements in the design of the FCX001 include a fan-driven anti-torque system, hybrid propulsion system, main rotor blade tips, extensive use of fuselage glass, winged doors and the use of augmented reality in the cockpit to control the aircraft. On the very roomy cabin ceiling of the aircraft, configured for only eight passengers in the Heli-Expo model, but able to adapt up to 12 passengers, Bell introduced a "drop-down" control module to allow personalization maximum and increased passenger comfort. The concept is provided with various modules that provide passengers with the ability to adjust their own things, such as cabin light intensity, interior temperature, or infotainment system. When looking closely at the new FCX-001 concept, starting with the back of the aircraft, it does not have a tail rotor (which is essential and notable for Bell's new model). In order to achieve the anti-torque instead, a new multi-rotor system is needed in the hood. It gives the aircraft the ability to push in both directions and also has vector control of the traction, also allowing it to give up a horizontal stabilizer. The anti-torque system is acted by an electric motor as part of a hybridized propulsion system. At the top of the aircraft, the main rotor blades (morphing) have an attractive design. At the same time, technology aims to allow the tip of each blade to move between the different flight regimes, just like a "swing wing" on an airplane to maximize efficiency and performance and 
reduce noise. The actual airframe of the aircraft is also very different from what Bell used in the past. In terms of ladder, the FCX-001 is slightly larger than a Bell 412 both in terms of its length and width, its new lines and its use of massive glass exhibiting some production challenges that rely on the new composite structures, today so widely used in the aviation and aerospace industries.

Some pilots are afraid of this type of concept without buttons, handles, devices, (not physically built), replaced (emulated) by software.

The new concept of driving with the software inspires the admiration and the fear of the pilot that he could be overcome and at a time of disruption of the software there could be a catastrophe in the absence of a classic, manual, mechanical, physical command. Pilot Bryan $\mathrm{W}$ goes so far as to say that the fear of driving this is so great that experienced pilots will not accept to become soft-assisted robots and to do so unless they will need a lot of money (Johnson, 2017).

This is what we believe is the essence. After airplanes without pilots, pilots are now fully coordinated by a central, universal system through satellites, computers, electronics, robotics and soft. The pilot no longer depends only on his reaction capabilities, but to the greatest extent he is permanently coordinated by software. Somehow the pilot becomes a robot and in some extreme situations he can't have the possibility of his will.

\section{Acknowledgement}

We acknowledge and thank Mr Taher M. AbuLebdeh, Associate Prof at North Carolina A and T State University, United States, for his suggestions and comments.

\section{Funding Information}

It's not necessary. The original article, after which this review has been taken, is "Bell Helicopter unveils futuristic FCX-001 concept aircraft" (Johnson, 2017). Through this work, the authors want to express their views on this new concept. The basic problem of this new concept is that if the software interrupts even for a second, if it catches a virus, all the emulged commands in the software disappear (even the pilot's lever hand), the pilot becomes powerless, he can only then say his last prayer. Such a concept contravenes the aviator's ethics and does not even respect the basic rules of flight safety from the start.

\section{Author's Contributions}

All the authors contributed equally to prepare, develop and carry out this manuscript.

\section{Ethics}

This article is a review and the original article, after which this review has been taken, is "Bell Helicopter unveils futuristic FCX-001 concept aircraft" (Johnson, 2017). The authors want to highlight and discuss some important issues regarding this new prototype. The original article, after which this review has been taken, is "Bell Helicopter unveils futuristic FCX-001 concept aircraft" (Johnson, 2017). Through this work, the authors want to express their views on this new concept. The basic problem of this new concept is that if the software interrupts even for a second, if it catches a virus, all the emulged commands in the software disappear (even the pilot's lever hand), the pilot becomes powerless, he can only then say his last prayer. Such a concept contravenes the aviator's ethics and does not even respect the basic rules of flight safety from the start.

The corresponding author confirms that all of the other authors have read and approved the manuscript and no ethical issues involved.

\section{References}

Aversa, R., D. Parcesepe, R.V. Petrescu, G. Chen and F.I.T. Petrescu et al., 2016a. Glassy amorphous metal injection molded induced morphological defects. Am. J. Applied Sci., 13: 1476-1482.

Aversa, R., R.V. Petrescu, F.I.T. Petrescu and A. Apicella, 2016b. Smart-factory: Optimization and process control of composite centrifuged pipes. Am. J. Applied Sci., 13: 1330-1341.

Aversa, R., F. Tamburrino, R.V. Petrescu, F.I.T. Petrescu and M. Artur et al., 2016c. Biomechanically inspired shape memory effect machines driven by muscle like acting NiTi alloys. Am. J. Applied Sci., 13: 1264-1271.

Aversa, R., R.V. Petrescu, R. Sorrentino, F.I.T. Petrescu and A. Apicella, 2016d. Hybrid ceramo-polymeric nanocomposite for biomimetic scaffolds design and preparation. Am. J. Eng. Applied Sci., 9: 1096-1105.

Aversa, R., V. Perrotta, R.V. Petrescu, C. Misiano and F.I.T. Petrescu et al., 2016e. From structural colors to super-hydrophobicity and achromatic transparent protective coatings: Ion plating plasma assisted $\mathrm{TiO}_{2}$ and $\mathrm{SiO}_{2}$ Nano-film deposition. Am. J. Eng. Applied Sci., 9: 1037-1045.

Aversa, R., R.V. Petrescu, F.I.T. Petrescu and A. Apicella, 2016f. Biomimetic and evolutionary design driven innovation in sustainable products development. Am. J. Eng. Applied Sci., 9: 1027-1036.

Johnson, O., 2017. Bell Helicopter unveils futuristic FCX-001 concept aircraft. Vertical Magazine. 
Mirsayar, M.M., V.A. Joneidi, R.V.V. Petrescu, F.I.T. Petrescu and F. Berto, 2017. Extended MTSN criterion for fracture analysis of soda lime glass. Eng. Fracture Mechan., 178: 50-59. DOI: $10.1016 /$ j.engfracmech.2017.04.018

Petrescu, R.V. and F.I. Petrescu, 2013a. Lockheed Martin. 1st Edn., CreateSpace, pp: 114.

Petrescu, R.V. and F.I. Petrescu, 2013b. Northrop. 1st Edn., CreateSpace, pp: 96.
Petrescu, R.V. and F.I. Petrescu, 2013c. The Aviation History or New Aircraft I Color. 1st Edn., CreateSpace, pp: 292.

Petrescu, F.I. and R.V. Petrescu, 2012. New Aircraft II. 1st Edn., Books On Demand, pp: 138.

Petrescu, F.I. and R.V. Petrescu, 2011. Memories About Flight. 1st Edn., CreateSpace, pp: 652. 